Western University

Scholarship@Western

Education Publications

Education Faculty

2014

Further Evidence of the Comparative Memorability of Alliterative Expressions in Second Language Learning

Frank Boers

Western University, fboers@uwo.ca

Seth Lindstromberg

Hilderstone College, UK

Stuart Webb

The University of Western Ontario, swebb27@uwo.ca

Follow this and additional works at: https://ir.lib.uwo.ca/edupub

Part of the Education Commons

Citation of this paper:

Boers, F., Lindstromberg, S., \& Webb, S. (2014). Further evidence of the comparative memorability of alliterative expressions in second language learning. RELC Journal, 45(1), 85-100. 


\section{Further Evidence of the Comparative Memorability of Alliterative Expressions in Second Language Learning}

\section{Frank Boers}

Victoria University of Wellington, New Zealand

\section{Seth Lindstromberg}

Hilderstone College, UK

\section{Stuart Webb}

Victoria University of Wellington, New Zealand 


\section{Abstract}

Previous research has furnished evidence that alliterative expressions (e.g. a slippery slope) are comparatively memorable for second language learners, at least when these expressions are attended to as decontextualized items (Lindstromberg and Boers, 2008a; Boers et al., 2012). The present study investigates whether alliteration renders lexical phrases comparatively memorable also when these phrases are encountered in texts read primarily with a focus on content. Fifty-four EFL students read a text adapted so as to include five instances of 12 idiomatic expressions. The results of surprise post-tests suggest that the alliterative phrases among these target expressions left significantly stronger memory traces than the non-alliterative ones, especially regarding the form or composition of the phrases.

\section{Keywords}

Lexical phrases, collocations, idioms, alliteration, incidental learning, repetition, memory 


\section{Introduction}

Language abounds with lexical phrases (Nattinger and DeCarrico, 1992; Pawley and Syder, 1983; Wray, 2002), and it is therefore not surprising that knowledge of a sizeable phrasal repertoire helps second and foreign language learners (henceforth L2 learners) come across as proficient L2 users (Boers et al., 2006; Dai and Ding, 2010; Hsu and Chiu, 2008; Keshavarz and Salimi, 2007; Stengers et al., 2011). Not only does mastery of lexical phrases help learners produce 'idiomatic' (i.e. nativelike) language, it also helps them process L2 input more efficiently (Arnon and Snider, 2009; Ellis et al., 2008; Siyanova-Chanturia et al., 2011). However, L2 learners have been shown to be remark- ably slow at mastering the phrasal dimension of their target language (Kuiper et al., 2009; Laufer and Waldman, 2011; Li and Schmitt, 2010; Stengers et al., 2010). Among the explanations that have been proposed to account for this slow uptake are, on the one hand, the lack of attention that learners give to phrases they experience as semantically transparent (Boers et al., 2014) and, on the other hand, learners' misinterpretation of phrases whose meaning transcends that of the constituent words (Martinez and Murphy, 2011).

Diverse pedagogic proposals have been made in recent years with a view to fostering L2 phrase learning. Some suggest ways of helping 
students engage with and remember particular lexical phrases they encounter during classroom activities (Boers and Lindstromberg, 2009; Davis and Kryszewska, 2012; Laufer and Girsai, 2008; Lindstromberg and Boers, 2008b). Others, recognizing that classroom time is typically too short to give explicit attention to more than a minute fraction of the vast phrasal resource of the language, promote independent study outside the classroom (McCarthy and O'Dell, 2005), and/or recommend using classroom time to raise students' awareness of the importance of the phrasal dimension of language, rather than trying to teach individual phrasal expressions (Lewis, 1997). In a similar vein, some researchers have explored the possibility of increasing the likelihood of 'incidental' acquisition of lexical phrases (i.e. the uptake of lexical phrases as a byproduct of message-oriented activities such as reading for pleasure or interest) by making selected lexical phrases stand out in reading texts through typographic enhancement (e.g. underlining) (Bishop, 2004; Peters, 2009, 2012) or through repetition (Webb et al., 2013).

Webb et al. (2013) incorporated target lexical phrases in a graded reader for EFL learners and created versions of the text where the same phrases were used multiple times, ranging from five to 15 times. Learners were given one of the versions to read and subsequently their recollections of the form and the meaning of the target phrases was 
tested. The participants who had read the version of the text in which each target phrase occurred just once did not do any better in the post-test than a control group, who had not been exposed to the targets at all. Measurable uptake of the phrases from reading occurred from five encounters upwards, and, as expected, the more often the phrases were encountered during reading, the better the scores were in the post-test which parallels earlier findings concerning uptake of single words (Waring and Takaki, 2003).

Webb et al. (2013) compared mean post-test results between the reading conditions, but they did not investigate whether some of the target phrases stood a better chance of being picked up from the text than others. It is quite conceivable that particular traits of lexical phrases may facilitate or hinder (aspects of) their incidental acquisition. It stands to reason, for example, that the degree of semantic transparency will influence the pace at which the meaning of a phrase is acquired (compare, e.g. make a mistake and make the grade). On the other hand, if the learner experiences a phrase as crystal clear, he or she may not give much attention to its lexical makeup, and this may explain why learners' L2 output often shows signs that they are led astray by incongruous L1 collocations (e.g.*do a mistake), even at advanced levels of L2 proficiency (Laufer, 2011; Nesselhauf, 2005). Regarding the learning of 
the lexical composition (i.e. the form) of phrases, Boers et al. (2012) argue that word pairs manifesting alliteration (e.g. private property; full force) tend to be remembered better than non-alliterative counterparts (e.g. private collection; full speed). It is this potential mnemonic privilege enjoyed by alliterative lexical phrases that we further explore in the present article.

If it were true that alliterative phrases enjoy a comparative advantage in contexts of incidental learning, then the textual enhancement techniques we mentioned above could easily exploit that advantage. This is not a trivial pursuit, particularly in TESOL, because alliteration is a very common feature of English phraseology at large, including idioms (from pillar to post), similes (good as gold), binomials (toss and turn), compounds (beer belly) and collocations (wage war). Boers and Lindstromberg (2009: 114) collected 5,667 phrasal lexemes from the Macmillan English Dictionary for Advanced Learners (2007, 2nd edition) and found that no fewer than $737(13 \%)$ of these alliterate. According to Boers and Stengers (2008), 17\% of the entries in the Collins Cobuild Dictionary of Idioms (2002, 2nd edition) alliterate.

Empirical studies of the memorability of alliteration are rare, which is surprising given the conspicuous use of alliteration in slogans (e.g. Put a tiger in your tank), names of fiction characters (Mickey Mouse; Donald 
Duck) and film and book titles (e.g. Bend it Like Beckham; Pride and Prejudice), which hints at a belief in its 'catchiness'. In the realm of TESOL, Lindstromberg and Boers (2008a) reported an experiment where alliterative phrases were found to be recalled significantly better by their EFL participants than non-alliterative controls. However, this result was obtained after the participants had been asked (as part of the treatment stage) to look for alliteration in the set of target phrases, and may thus have been task-induced rather than a manifestation of the memorability of alliteration per se. To our knowledge, the aforementioned study by Boers et al. (2012) was the first to test the hypothesis that alliteration renders lexical phrases comparatively memorable for L2 learners also in the absence of awareness-raising about the presence of alliteration. Alliterative collocations and non-alliterative controls were merely dictated to the participants, who were subsequently asked to recall as many of the dictated collocations as they could. Significantly more alliterative targets were recalled than controls in this immediate post-test. A partial replication study is reported in Boers et al. (in press), where a similar advantage for the alliterative targets was attested, again at least in an immediate post-test.

Writing down decontextualized word pairs in a dictation activity is, of course, a different experience from something we do much more often in 
life, namely reading a text with a focus on its content. It is safe to say that a dictation of the sort used in the aforementioned experiments engages participants more directly with linguistic form than extensive reading does. Whether alliterative phrases are comparatively memorable for L2 learners also when they process text with a primary focus on the content of the text (i.e. with a focus on meaning) is the principal research question we address in this study. A secondary research question is whether the advantage (if any) extends beyond learning the form or lexical makeup of the phrases to learning their meaning. Even though alliteration can contribute to the semantics of phrases that display iconicity, such as onomatopoeia (e.g. chook-chook) and phrases that exploit sound-symbolic phoneme clusters (i.e. phones- themes) more generally (e.g. such as crispy crust and flip flops), alliteration is more often a formal feature than a semantic one, at least in English phraseology. According to transfer-of-processing theory, one would expect the attention that is attracted by a formal trait to positively influence first and foremost the retention of that formal trait, while semantic processing is required for retention of meaning (e.g. Barcroft, 2002).

The present study is a follow-up of Webb et al.'s (2013) study. Highintermediate EFL learners read a text that contained multiple instances of target phrases, some of which alliterate. Subsequently, their recollection 
of these phrases was measured in surprise tests. We then compared the participants' test performance on the alliterative and the non-alliterative items.

\section{Method}

\section{Participants}

The participants in this study were 54 Japanese native speakers (26 men and 28 women) from 14 first- and second-year EFL classes at 3 universities in Japan. All of the participants had received formal English language instruction for at least 7 years. The 2000 word level of the Vocabulary Levels Test (Schmitt et al., 2001) was administered to 41 of the participants (three classes did not complete the test). Their average raw score was 20.39/30.

\section{Materials}

The Text. The text we asked the participants to read was a modified version of the Oxford Bookworms graded reader New Yorkers (Henry et al., 2000). It was made up of four short stories, which we believed would keep the participants more engaged than one longer story. The stories were originally written by $\mathrm{O}$. Henry and describe humorous events in the lives of several characters living in New York at the beginning of the 
$20^{\text {th }}$ century. New Yorkers is a Stage 2 graded reader. Stage 2 graded readers are limited to 700 high- frequency headwords and, given the participants' profile, these words were likely to be known to these learners. Additional sentences were created and inserted into New Yorkers to incorporate each of the target phrases five times. Five encounters were found sufficient for measurable learning to occur in the study by Webb et al. (2013). We felt that incorporating more than five instances would make the text too contrived and would lack plausibility as an example of text adaptation for pedagogic purposes. All of the inserted sentences were also made up of high-frequency words (see below). The instances of the phrases were distributed semi-randomly across the text so that each of the stories that made up the text contained at least one instance of each phrase.

The Tests.Two tests measuring receptive knowledge of form (i.e. the lexical composition) and the form-meaning connection of the target collocations were administered to the participants on three occasions: one week before the treatment, immediately after the treatment, and one week after the treatment. None of the tests were announced before-hand to minimize the likelihood that students would engage in deliberate study of the phrases in the time interval between two test administrations. The receptive test in writ- ten form had a multiple-choice format; the 
participants were presented with the verb and were required to indicate the most likely noun collocate from six options. The options included the correct collocate, four distracters, and an I don't know choice. For example, lose was given as the cue, and the participants were asked to choose from (a) cigarette, (b) touch, (c) demand, (d) meat, (e) church, and (f) I don't know. All of the distracters were checked for their (lack of) statistical strength of co-occurrence with the cues to ensure that none of the distracters might be considered acceptable collocates. For example, the collocation lose touch was encountered 142 times in the British National Corpus (Davies, BYU site) and had a mutual information score (indicating the likelihood of co-occurrence of the two words) of 3.67. In comparison, none of the distracters had a positive mutual information score and the most frequently encountered distracter for lose (meat) was encountered only 6 times within a span of plus or minus four in the corpus. The distracters were all words which occurred in the text, New Yorkers. The instructions were presented in both English and Japanese. In the second test, which measured receptive knowledge of meaning, the participants were presented with the target collocations (e.g. lose touch; run the risk) and were required to write their meanings in L1 (i.e. Japanese). The instructions were presented in both the L1 and L2 and asked the participants to write the meaning of the phrase if you know it. 
The participants' Japanese renderings of the meaning of the English target phrases were scored by a bilingual user of Japanese and English. All responses that indicated understanding of the meanings of the phrases as a whole (e.g. face the fact = 'accept the reality'; 'accept the bad situation'), rather than just the meanings of the individual words, were scored as correct. In cases of doubt, a second opinion was sought, from another bilingual user of English and Japanese. The Target Phrases. The target phrases were the following 12 verb-noun collocations: cut corners, run the risk, face the fact, break the silence, raise the question, spread the word, reach a decision, buy time, meet the demand, lose touch, stay the course and lose strings. The strength of collocation of the verb - noun combinations of the phrases was verified in The Bank of English (i.e. the corpus that informs the Collins Cobuild publications). Their T-scores ranged from 5.44 (buy-time) to 28.38 (meet-demand). T-scores indicate the strength of co-occurrence of two words. A higher T-score indicates a greater strength of co-occurrence. A T-score of 2 or higher indicates a likelihood of co-occurrence of words that is statistically significant (Barnbrook, 1996: 98).

These 12 target phrases are expressions whose meaning is not straightforwardly derivable from the primary meanings of the constituent words (unlike cause damage, for example). By virtue of this 'non- 
compositionality', they could be categorized as idioms - most of them are indeed listed in the Collins Cobuild Dictionary of Idioms (2002, 2nd edition), for example.

It needs mentioning that the text with its embedded target phrases was not designed specifically for the present study but borrowed from Webb et al.'s (2013) study on incidental phrase learning. Three of the 12 target collocations in those materials (cut corners, run the risk and face the fact) manifest alliteration (i.e. repetition of word-initial consonants). This ratio of alliterative vs. non-alliterative phrases in the sample is quite natural, given the aforementioned counts of alliteration in English phraseology (e.g. Boers and Stengers, 2008). Put differently, it is a ratio that lends a degree of 'ecological' validity to the use of this text for the purpose of our experiment. It is also a ratio that is unlikely to raise the participants' awareness that alliteration is the variable of interest in a study.

Apart from the presence or absence of alliteration, other factors may influence the likelihood and pace of acquisition of lexical phrases. Presumably the most important of those variables is degree of semantic transparency. Steinel et al. (2007) found that the learnability of idioms in the context of deliberate learning was strongly associated with the degree of semantic transparency of the idioms - as rated by the population of learners from which the participants in their experiment were drawn. 
Whether an expression is perceived to be semantically transparent itself depends on several factors. For one thing, it will hinge on whether the constituent words of the expression are known in the first place. All of the words that made up the target expressions in our study were likely to be known to the participants because they were included in either West's (1953) General Service List or Nation's (2006) list of the most frequent 2000 word families (based on counts in the British National Corpus). The degree of semantic transparency of an L2 idiom is also influenced by the availability in the learner's mother tongue (or another language she is familiar with) of a congruent expression (e.g. Charteris-Black, 2002). None of the target phrases had close translation equivalents in Japanese, i.e. the mother tongue of our participants. The role of the mother tongue does imply, however, that it is hard for teachers/ researchers to reliably estimate whether a given phrase will be experienced as opaque or transparent by L2 learners whose L1 they do not share. To obtain ratings for the relative semantic transparency of the 12 target phrases from the perspective of L1 Japanese speakers, we included them in a list of English expressions (accompanied by their translations) which we asked a different group of Japanese native speakers $(N=33)$, who were students enrolled in a TESOL MA programme, to rate on a scale from 1 (not at all transparent, e.g. shoot the 
breeze) to 7 (very transparent, e.g. read a book). Their mean rating for the three alliterative phrases was 4.9 and for the non-alliterative ones it was

5.3. Degree of transparency is therefore an unlikely intervening variable in case the learning gains in our sample are found to be the greatest for the set of alliterative phrases.

Apart from semantic transparency, several other factors may potentially influence the pace of incidental uptake of a lexical phrase. These include the length of the phrase, the time interval between encounters with the phrase, and the degree of concreteness or imageability of its meaning. We will return further below (in the discussion section) to the question whether these (and other) factors can help explain the differential uptake of the target phrases in our study.

\section{Procedure}

Data was collected over a three week period. In the first week, the participants were given two pre-tests to measure their knowledge of the target collocations. In the second week, the participants received the modified version of New Yorkers. The participants read the text while listening to an audio version of the graded reader. The audio version was recorded by a native speaker of English at a pace (156 words per minute) that had been found appropriate for English language learners of a 
similar profile in Webb et al.'s (2013) study. The duration of the recording was 34 minutes and 32 seconds. A limitation of earlier research that investigated incidental vocabulary learning through reading was that because participants' reading speed varied, in some cases they were unable to complete the readings and tests (Pitts et al., 1989). By having the participants read and listen to the text, the design ensured that the participants would complete the reading with sufficient time to complete the post-tests within a 90 minute class period. This procedure had been successfully applied in earlier studies that examined incidental learning of single word items (Horst et al., 1998) and was also used in the aforementioned study on lexical phrases by Webb et al. (2013).

Immediately after the participants finished reading and listening to the text, the two tests measuring the participants' knowledge of the target phrases were administered. In the third week of the study, the same two tests were administered once more to the participants. The tests were completed in the same order on each administration; the test measuring receptive knowledge of written form was completed and collected prior to the receptive test of form-meaning connection. The order of the items was randomized within and between tests on all occasions. Each time the tests were administered, the participants had 10 minutes to complete each test (20 minutes in total). We need to acknowledge that, in a pre-test to post- 
test design, it is hard to eliminate test-taking effects (e.g. the possibility that participants' might retain information from the pre-test and attend more to the target phrases during the reading activity than they would otherwise). However, there seems to be no reason to suspect that such test-taking effects as such would differently affect the pace of uptake of the alliterative and the non-alliterative targets in this within-participant study.

\section{Results}

The numbers of correct test responses and gains between the pre-test and the post-tests are given per target phrase in Tables 1 and 2. Table 1 presents the data from the receptive knowledge-of-form test (the verb noun multiple-choice test); Table 2 presents the data from the receptive knowledge-of-meaning test (the translation test). The statistical analyses that follow (including the regression analyses reported in the discussion section) were performed on http://www.vassarstats.net and http://www.wessa.net/.

The scores from the immediate and delayed form-focused post-tests show an extremely strong correlation $\left(r_{S} .90\right)$, as do the scores from the two post-tests focusing on meaning $\left(r_{S} .96\right)$. The correlations between the tests on form and the tests on meaning are not as strong $\left(r_{S} .61\right.$ immediate; $r_{S} .58$ delayed) 
The mean gain of form knowledge between the pre-test and the post-test is markedly greater for the set of alliterative phrases than for the nonalliterative ones-immediate post-test: mean difference $(M D)=.22$; $S D \mathrm{~s}=.04^{\text {Allit }} / .09^{\text {Other }} ; r_{\mathrm{pb}}=.80 ; t(10)=4.26 ; p<.0001,1$-tailed; delayed post-test: $M D=.13 ; S D_{\mathrm{s}}=.02 / .05 ; r_{\mathrm{pb}}=.93 ; t(10)=8.02 ; p$ $<.0001)$. Both of these $p$ values easily satisfy the more rigorous alpha level of $\leq .01$ that is sometimes recommended in the case of results from small samples (Allison, 2006). Semantic transparency also correlates positively with gains, but this correlation is rather weak $\left(r_{s} .28\right.$ immediate; $r_{S} .22$ delayed) and not significant ( $p .20$ and $p .25,1$-tailed). 
Table I. Knowledge of Form (Multiple-Choice Test).

\begin{tabular}{|c|c|c|c|c|c|}
\hline \multirow[b]{2}{*}{ Target phrase } & \multirow{2}{*}{$\begin{array}{l}\text { Pre-test } \\
\text { Correct }\end{array}$} & \multicolumn{2}{|c|}{ Immediate post-test } & \multicolumn{2}{|c|}{ Delayed post-test } \\
\hline & & Correct & Gain & Correct & Preserved gain \\
\hline Cut corners & 19 & 34 & 15 & 29 & 10 \\
\hline Run the risk & 16 & 30 & 14 & 28 & 12 \\
\hline Face the fact & 17 & 30 & 13 & 28 & II \\
\hline Sub mean & & & 14 & & $I I$ \\
\hline Target phrase & Correct & Correct & Gain & Correct & Preserved gain \\
\hline Break the silence & 19 & 30 & 11 & 24 & 5 \\
\hline Raise questions & 16 & 25 & 9 & 17 & 1 \\
\hline Spread the word & 6 & 16 & 10 & 12 & 6 \\
\hline Reach a decision & 13 & 21 & 8 & 17 & 4 \\
\hline Buy time & 5 & 12 & 7 & 9 & 4 \\
\hline Meet a demand & II & 17 & 6 & II & 0 \\
\hline Lose touch & 1 & 6 & 5 & 2 & 1 \\
\hline Stay the course & 2 & 6 & 4 & 5 & 3 \\
\hline Pull strings & 17 & 19 & 2 & 18 & I \\
\hline Sub mean & & & 6.9 & & 2.8 \\
\hline
\end{tabular}

Table 2. Knowledge of Meaning (Translation Test).

\begin{tabular}{lccccc}
\hline & Pre-test & \multicolumn{2}{l}{ Immediate post-test } & \multicolumn{2}{l}{ Delayed post-test } \\
\cline { 2 - 6 } Target phrase & Correct & Correct & Gain & Correct & Preserved gain \\
\hline Cut corners & 0 & 0 & 0 & 0 & 0 \\
Run the risk & 13 & 23 & 10 & 19 & 6 \\
Face the fact & 8 & 16 & 8 & 13 & 5 \\
Sub mean & & & 6 & & 3.7 \\
\hline Target phrase & Correct & Correct & Gain & Correct & Preserved gain \\
\hline Break the silence & 21 & 27 & 6 & 24 & 3 \\
Raise the question & 5 & 12 & 7 & 11 & 6 \\
Spread the word & 0 & 1 & 1 & 0 & 0 \\
Reach a decision & 2 & 3 & 1 & 3 & 1 \\
Buy time & 0 & 0 & 0 & 0 & 0 \\
Meet the demand & 5 & 8 & 3 & 5 & 0 \\
Lose touch & 0 & 0 & 0 & 0 & 0 \\
Stay the course & 0 & 0 & 0 & 0 & 0 \\
Pull strings & 0 & 0 & 0 & 0 & 0 \\
Sub mean & & & 2 & & 1. I \\
\hline
\end{tabular}


In the two post-tests on the meaning of the phrases, the set of alliterative phrases was again recalled best, but significance is narrowly missed-immediate: $M D=.10 ; S D_{\mathrm{s}}=.18^{\text {Allit }} / .11^{\text {Other }} ; r_{\mathrm{pb}}=.45 ; t(10)=$ $1.57 ; p=.07,1$-tailed; delayed: $M D=.08 ; S D \mathrm{~s}=.11 / .07 ; r_{\mathrm{pb}}=.44 ; t(10)=$ $1.56 ; p=.07$. As was to be expected, in the meaning-test data it is semantic transparency that shows the strongest (positive) correlations with gain-immediate: $M D=.13 ; S D_{\mathrm{s}}=.02 / .05 ; r_{\mathrm{S}}=.72 ; t=3.29 ; p=$ $.004,1$-tailed; delayed: $M D=.08 ; S D_{\mathrm{s}}=0.09 / .07 ; r_{\mathrm{S}}=.59 ; t=2.34 ; p=$ .02. That the correlation is weaker in the delayed post-test may be due to the high proportion of tied scores (more particularly 0 scores) in that test.

Summing up, the results suggest that alliteration is an influential factor in fostering form knowledge (as measured by the multiple-choice test). When it comes to gains at the level of meaning knowledge, the degree of semantic transparency of the phrase appears most influential, but the presence of alliteration appears to be a contributing factor here as well.

\section{Discussion}

Despite the striking advantage of the alliterative phrases attested in our data, particularly in the tests of knowledge of form, the question arises whether other variables might also account for the superior learning gains 
of these target items. In this section we assess the plausibility of a range of alternative explanations.

Apart from semantic transparency, another semantic factor known to facilitate vocabulary learning is concreteness of meaning. Owing to their imageability, items with concrete meanings are easier to commit to memory than items with abstract meanings (e.g. Hamilton and Rajaram, 2001; Walker and Hulme, 1999). While the idiomatic meaning of the expressions used in our study is obviously not concrete (e.g. nothing gets physically broken when one breaks the silence, and it is unlikely that physical running is involved when one runs risks), some of these phrases may evoke imagery more readily than others. Moreover, the aforementioned study by Steinel et al. (2007) showed that imageability indeed facilitates idiom learning (at least during deliberate memorization). To examine whether a difference in degree of imageability might account for the better uptake of the alliterative phrases, we obtained three nativespeaker volunteers' independent ratings on a five-point scale of the degree of imageability of the 12 target phrases. The mean ratings for the three alliterative targets and for the others differed by only 0.1 point. Besides, correlations between imageability ratings and learning gains for the 12 targets were found to be weak and negative in our data. We can therefore safely discard degree of imageability as an alternative 
explanation for the superior learning of the alliterative target phrases in our sample.

As explained above, our test of form knowledge gave participants the verb of the collocation as a cue and participants were required to choose the matching noun collocate from a list. In case concreteness of meaning were to affect that choice, we asked three collaborators to rate the 12 nouns on a scale from 1 (least concrete) to 5 (most concrete). The ratings suggest the nouns of the alliterative phrases were deemed on average slightly less concrete than the nouns of the non-alliterative ones (3.2 vs. 3.8). Besides, also here it turned out that correlations between concreteness and learning gains attested in our data were weak and negative, and so this potential explanation for better scores can also be excluded.

Several formal features apart from alliteration may conceivably influence the learnability of the target phrases. First, the length of vocabulary items may make them harder to learn (Ellis and Beaton, 1993: 568). But while the mean number of syllables of the content words is 2.3 for the alliterative targets and 2.5 for the non-alliterative ones, we found a moderate but positive correlation of $r_{s}$. 30 between number of syllables and learning attested in the immediate post-test of form knowledge. This means that the longer nouns may actually have stood a 
better chance of being learned than the shorter ones, and so this variable too fails to explain the better learning attested for the alliterative phrases in our sample. Second, in case morphological variability (e.g. ran the risk/ running the risk) might interfere with recognition of the sameness of re-encountered phrases, we also counted the number of different inflected forms per target phrase in the text ( $M 1.0$ vs. $M 0.9)$. This last trait correlated with learning gains in our data so weakly $\left(r_{s}\right.$ values close to nil) that it was clearly not a factor that affected uptake. Third, the presence of function words (e.g. an article or a pronoun) between the content words might perhaps hinder the swift formation of an association between the two content words. We therefore counted the mean number of function words between the content words across the five occurrences of each target phrase in the text, yielding means of 0.7 (for alliterative targets) and 1.0 (for the others). Here, we found a negative correlation ( $r_{s}$ -.22) with the scores on the immediate form-knowledge post-test, which might indicate a small advantage for the alliterative targets in our sample.

Although prior knowledge of the target collocations was verified by means of a pre- test, we felt it prudent to take account also of a number of factors that might have rendered (parts of) some phrases more familiar than others as a result of exposure to English prior to the experiment. We 
used frequency data from Mark Davies' Corpus of Contemporary American English (COCA) site as a rough estimate of the likelihood that participants might have come across any of the target phrases before. This yielded a mean number of 584 hits for the alliterative targets and 1075 for the others. The likelihood of prior encounters with some of the target phrases is therefore not a plausible explanation for the better learning gains attested for the alliterative phrases in our sample. Given that one of our tests asked the participants to recognize the noun that is associated with a given verb, we also looked up corpus frequencies of these nouns, in case degree of familiarity with a word influences its selection during test taking. We found no evidence of this at all $\left(r_{s}\right.$ values close to nil).

The way the 12 target phrases were inserted and distributed in the text is another factor that may have influenced learning. Given that each lexical phrase was used five times in the text, an overall skewedness in availability of contextual clues is unlikely. To be on the safe side again, a research assistant who was blind to the purpose of the study was asked to evaluate the passages containing the target phrases for their naturalness and to ascertain that none of the instances of a phrase was accompanied by appositive cues (an accompanying paraphrase or synonym that clarifies an item's meaning (Watanabe, 1997). An effort had been made to distribute the 
12 phrases evenly across the text, but the content of the text itself inevitably determined to some extent where given phrases could fit naturally. It could be argued that meeting the same item twice in a very short time span is more likely to consolidate a fleeting memory left by the earlier encounter than if one re-encounters an item after a longer time interval (because the earlier memory trace may by then already have faded away). We therefore counted the smallest number of words in the text between two occurrences of each target phrase. This yielded means of 475 words for the alliterative targets and 386 words for the non-alliterative ones, and so it seems this variable was not to the advantage of the former either. Finally, we ascertained that instances of the three alliterative targets were not coincidentally the last to be encountered in the text because this might privilege their recall in the immediate post-test. In any case, it turned out that recency of last encounter and immediate post-test performance correlated negatively (rho $-.22)$ in our data.

In sum, it seems that very few factors apart from the presence of alliteration itself can help account for the superior learning gains attested for the alliterative phrases in our sample. It was nevertheless worth performing exploratory multiple regression analyses to verify whether some of the variables do not help explain the variance in the data to some extent. Concerning the gains between the pre-test and the immediate post- 
test of form knowledge, a multiple regression model including only the variables of alliteration and transparency yields a remarkably high adjusted (adj.) $R^{2}$ value of .71 (which suggests that these two variables alone account for $71 \%$ of the variation in gain). A slightly higher adj. $R^{2}$ value of .74 is reached only if we add the variable of number of syllables to the model. In the delayed post-test of form knowledge, the variables of alliteration and transparency alone account for $86 \%$ of the variance - which is remarkably high.

The model accounting for the greatest proportion of variation in the gains between pre-test and immediate post-test on knowledge of meaning (i.e. the translation test) again includes just the variables semantic transparency and alliteration, yielding adj. $R^{2}=.45$. As regards the gains attested in the delayed post-test for meaning, a model with only transparency and alliteration produces $R^{2}=39$. Rather intriguingly, this model is improved upon by adding corpus frequency of the phrases to the $\operatorname{mix}$ (yielding $R^{2}=.55$ ). Perhaps the more frequent phrases (e.g. raise the question) stood a better chance than the less frequent ones (e.g. pull strings) of being re-encountered by the participants during the one-week interval between the reading activity and the delayed post-test. In any case, all of the models we tried without the variable of alliteration produced lower $R^{2}$ values than those with this variable included, which corroborates 
the thesis that alliteration positively influenced the learning of formmeaning connections as well as the learning of form only.

\section{Conclusions}

The above findings support the thesis that alliteration can render lexical phrases comparatively memorable also under incidental learning conditions. Unsurprisingly, the effect was found strongest in the tests on knowledge of form. As was to be expected, the degree of semantic transparency played the greater part in the acquisition of the meaning of the lexical phrases.

The extremely low scores in the translation test are striking: For half of the target phrases no long-term gains in meaning-learning were attested. This is remarkable, considering the fact that each expression had been met in context five times, giving the participants ample opportunity for developing form-meaning associations.

Somewhat surprising also is the finding that alliteration may positively affect not only learners' retention of the form but also their learning of the meaning of lexical phrases. It may be that the attention given to the alliterative phrases spilled over to the passages in which they occurred - each passage potentially providing an opportunity to create, fine-tune, or consolidate a form-meaning association. We 
acknowledge, though, that this must remain as speculation for now. We have no independent evidence (such as evidence from eye-tracking) that our participants actually paid more attention to the alliterative phrases than the non-alliterative ones while they were reading the text.

There are at least three other important reasons why we need to be cautious in drawing conclusions. For one thing, the participants listened to an audio recording of the text while they read it, which may have increased the perceptual salience of alliteration. Follow-up studies would need to test whether alliterative phrases have a comparative advantage for incidental uptake also from silent reading. Second, the tests we used were measures of receptive knowledge only. It is not certain, for example, that significantly better scores would be attested for alliterative expressions in cued recall (rather than recognition) tests. Third, the sample of target phrases in our study was very small. While this lent a certain degree of ecological validity to the experiment (which would have been lacking, for example, if we had inserted an excessive number of alliterative expressions in the text), it is clear that partial replications with different samples of target phrases would be welcome to verify whether the better learning attested for the alliterative phrases in this small-scale study was not due to some other factor after all. In addition, it may be worth investigating whether alliterative phrases are 
comparatively memorable also by means of a counter-balanced betweengroups research design, where alliterative target phrases in one version of a text (read by one group of learners) are substituted by nonalliterative phrases in another version (read by another group), and vice versa.

If such partial replication and follow-up studies were to confirm the findings reported here, then it would seem that the effectiveness of 'flooding' reading texts with recurring lexical phrases as a technique of enhancing incidental learning will differ from one target phrase to the next, depending on semantic and formal traits of the targets at hand. It would seem that learners are likely to reap rewards from reading such adaptations fastest in the case of phrases that are both semantically transparent and phonologically (and perhaps orthographically) memorable. 


\section{Acknowledgements}

We are grateful to Paul Joyce and Kanako Maruo for helping with the recruitment of participants for this study. We also thank two anonymous reviewers for their helpful suggestions.

\section{Funding}

This research was supported by the University Research Fund of Victoria University of Wellington, grant ID 108444, awarded to the first author.

\section{Corresponding author:}

Frank Boers, Victoria University of Wellington, P O Box 600, Wellington, New Zealand. Email:

frank.boers@vuw.ac.nz 


\section{References}

Allison P (1999) Multiple Regression: A Primer. Thousand Oaks, CA: Pine Forge Press.

Arnon I, Snider N (2009) More than words: frequency effects for multi-word phrases. Journal of Memory and Language 62: 67-82.

Barcroft J (2002) Semantic and structural elaboration in L2 lexical acquisition. Language Learning 52: 323-63.

Barnbrook G (1996) Language and Computers: Practical Introduction to the

Computer Analysis of Language. Edinburgh,: Edinburgh University Press.

Bishop H (2004) The effect of typographic salience on the look up and comprehension of unknown formulaic sequences. In: Schmitt N (ed) Formulaic Sequences. Amsterdam: John Benjamins, 227-47.

Boers F, Lindstromberg S (2009) Optimizing a Lexical Approach to Instructed Second Language Acquisition. Basingstoke: Palgrave Macmillan.

Boers F, Stengers H (2008) Adding sound to the picture: an exercise in motivating the lexical composition of metaphorical idioms in English, Spanish and Dutch. In: Cameron L, Zanotto M, and Cavalcanti M (eds) Confronting Metaphor in Use: An Applied Linguistic Approach. Amsterdam: John Benjamins, 63-78.

Boers F, Lindstromberg S, and Eyckmans J (2012) Are alliterative word combinations comparatively easy to remember for adult learners? RELC Journal 43(1): 127-35.

Boers F, Lindstromberg S, and Eyckmans J (in press) Is alliteration mnemonic 
without awareness- raising? Language Awareness.

Boers F, Demecheleer M, Coxhead A, and Webb S (2014) Gauging the effects of exercises on verb-noun collocations. Language Teaching Research. 18(1): 54-74

Boers F, Eyckmans J, Kappel J, Stengers H, and Demecheleer M (2006) Formulaic sequences and perceived oral proficiency: putting a lexical approach to the test. Language Teaching Research 10(3): 245-61.

Charteris-Black J (2002) Second language figurative proficiency: a comparative study of Malay and English. Applied Linguistics 23: 104-33. Dai Z, Ding Y (2010) Effectiveness of text memorization in EFL learning of Chinese students. In: Wood D (ed) Perspectives on Formulaic Language: Acquisition and Communication. New York: Continuum, 71-87.

Davis P, Kryszewska H (2012) The Company Words Keep: Lexical Chunks in Language Teaching. Peaslake: Delta.

Ellis NC, Beaton A (1993) Psycholinguistic determinants of foreign language vocabulary learning. Language Learning 43: 559-617.

Hamilton M, Rajaram S (2001) The concreteness effect in implicit and explicit memory tests. Journal of Memory and Language 44: 96-117.

Henry O, Hedge T, and Bassett J (2000) New Yorkers: Short Stories [Oxford Bookworms Library Stage 2]. Oxford: Oxford University Press.

Horst M, Cobb T, and Meara P (1998) Beyond a clockwork orange: acquiring second language vocabulary through reading. Reading in a Foreign Language 11: 207-23. 
Hsu J-Y, Chiu C-Y (2008) Lexical collocations and their relation to speaking proficiency of college EFL learners in Taiwan. Asian EFL Journal 10: $181-204$.

Keshavarz MH, Salimi H (2007) Collocational competence and cloze test performance: a study of Iranian EFL learners. International Journal of Applied Linguistics 17: 81-92.

Kuiper K, Columbus G, and Schmitt N (2009) Acquiring phrasal vocabulary. In: Foster-Cohen S (ed.) Advances in Language Acquisition. Basingstoke: Palgrave Macmillan, 216-40.

Laufer B (2011) The contribution of dictionary use to the production and retention of collocations in a second language. International Journal of Lexicography 24: 29-49.

Laufer B, Girsai N (2008) Form-focused instruction in second language vocabulary learning: a case for contrastive analysis and translation. Applied Linguistics 29(4): 694-716.

Laufer B, Waldman T (2011) Verb-noun collocations in second language writing: a corpus analysis of learners' English. Language Learning 61(2): $647-72$.

Lewis M (1997) Implementing the Lexical Approach. Hove: LTP.

Li J, Schmitt N (2009) The acquisition of lexical phrases in academic writing: a longitudinal case study. Journal of Second Language Writing 18(2): 85102.

Lindstromberg S, Boers F (2008a) The mnemonic effect of noticing alliteration in 
lexical chunks. Applied Linguistics 29(2): 200-22.

Lindstromberg S, Boers F (2008b) Teaching Chunks of Language. Rum: Helbling Languages.

Martinez R, Murphy VA (2011) Effect of frequency and idiomaticity on second language reading comprehension. TESOL Quarterly 45: 267-90.

McCarthy M, O’Dell F (2005) English Collocations in Use: Intermediate. Cambridge: Cambridge University Press.

Moon R (ed.) Collins Cobuild Dictionary of Idioms, 2nd Edition (2002) Glasgow: HarperCollins Publishers.

Nattinger J, DeCarrico J (1992) Lexical Phrases and Language Teaching. Oxford: Oxford University Press.

Nation ISP (2006) How large a vocabulary is needed for reading and listening? Canadian Modern Language Review 63: 59-82.

Nesselhauf N (2005) Collocations in a Learner Corpus. Studies in Corpus Linguistics 14. Amsterdam: John Benjamins.

Pawley A, Syder F (1983) Two puzzles for linguistic theory: nativelike selection and nativelike fluency. In: Richards J, Schmidt R (eds) Language and Communication. London: Longman, 191-226.

Peters E (2009) Learning collocations through attention-drawing techniques: a qualitative and quantitative analysis. In: Barfield A, Gyllstad H (eds) Researching Collocations in Another Language: Multiple Perspectives. Basingstoke: Palgrave Macmillan, 194-207.

Peters E (2012) Learning German formulaic sequences: the effect of two 
attention-drawing techniques. Language Learning Journal 40: 65-79.

Pitts M, White H, and Krashen SD (1989) Acquiring second language vocabulary through reading: a replication of the Clockwork Orange study using second language acquirers. Reading in a Foreign Language 5: 27176.

Rundell M (ed.) (2007) Macmillan English Dictionary for Advanced Learners, $2^{\text {nd }} e d$. Oxford: Macmillan.

Siyanova-Chanturia A, Conklin K, and Schmitt N (2011) Adding more fuel to the fire: an eye- tracking study of idiom processing by native and nonnative speakers. Second Language Research 27: 251-72.

Steinel MP, Hulstijn JH, Steinel W (2007) Second language idiom learning in a paired-associate paradigm: effects of direction of learning, direction of testing, idiom imageability, and idiom transparency. Studies in Second Language Acquisition 29: 449-84.

Stengers H, Boers F, Housen A, and Eyckmans J (2010) Does 'chunking' foster chunk-uptake? In: De Knop S, Boers F, and De Rycker A (eds) Fostering Language Teaching Efficiency through Cognitive Linguistics. Berlin: Mouton de Gruyter, 99-117.

Stengers H, Boers F, Housen A, and Eyckmans J (2011) Formulaic sequences and L2 oral proficiency: does the type of target language influence the association? International Review of Applied Linguistics 49: 321-43.

Walker I, Hulme C (1999) Concrete words are easier to recall than abstract words: evidence for a semantic contribution to short-term serial recall. 
Journal of Experimental Psychology: Learning, Memory, and Cognition 25: 1256-71.

Waring R, Takaki M (2003) At what rate do learners learn and retain new vocabulary from reading a graded reader? Reading in a Foreign Language 15: $130-63$.

Watanabe Y (1997) Input, intake, and retention: effects of increased processing on incidental learning of foreign language vocabulary. Studies in Second Language Acquisition 19: 287-307.

Webb S, Newton J, and Chang ACS (2013) Incidental learning of collocation. Language Learning 63(1): 91-120.

West M (1953) A General Service List of English Words. London: Longman, Green and Co. Wray A (2002) Formulaic Language and the Lexicon. Cambridge: Cambridge University Press. 